increasingly travelling in cars, there is no national polices or laws for child safety seats in cars.

Methods A cross-sectional survey and semi-structured interview were conducted in the maternity departments of two hospitals in China. Parents of newborns were recruited after delivery and surveyed on their knowledge, attitudes and behaviours regarding child safety seats use. Pregnant women were also interviewed to learn about their views and decisions regarding child safety seats use. Both quantitative and qualitative methods were used to analyse the data collected.

Results Of a total of 242 parents of newborns recruited in the quantitative survey, $202(83.5 \%)$ parents had heard of child safety seats, and 149 (61.6\%) parents reported they would use child safety seats for their babies. Parents' knowledge, car ownership, occupation, and income were significantly associated with their decision regarding use of child safety seats. Three themes were identified from the qualitative interview of 30 pregnant women: (1) the pregnant women perceived child passenger safety as important; (2) the car ownership, and price and quality of child safety seats were major influencing factors of their decisions on use of child safety seats, and (3) lack of awareness and lack of laws requiring use were perceived to contribute to low use of child safety seats in China.

Conclusion Lack of knowledge and awareness on child passenger safety were found to be two most important factors associated with low use of child safety seats. Effective interventions are urgently needed to improve parents' knowledge before laws are enacted and implemented.

\section{ROAD TRAFFIC INJURIES AMONG MINORS IN KAZAKHSTAN}

Leonid Karp, Andrey Dubitsky, Tatiana Potapchyuk, Sholpan Akhelova. Astana Medical University

\subsection{6/injuryprev-2016-042156.512}

Background Road traffic injuries (RTI) among minors are the main problem in Public Health.

Methods The analysis of situation with RTI among minors was carried out on the basis of official statistical data.

Results In total 232 minors, including 19 children aged till one year died in various accidents on roads of the country in 2014. About 4,6 thousand more got various injuries.

The main reasons for the road accident happening because of children is a crossing of the road in an unspecified place, unexpected emergence because of transport and other objects, and also game on the carriageway. The vast majority of road accident with participation of children is because of drivers, and every 5 th road accident - because of young pedestrians.

Today there are several main reasons concerning a condition of road safety. If in 2007 there were 2.5 min units of motor transport, in 2013 this figure grew to $4.1 \mathrm{~min}$.

Among the minor victims of road accident in Kazakhstan 89 were lost on passenger seats, thus more than a half of them children are younger than 7 years. In most cases injured children were transported in cars with violation of the rules of transportation of children their parents.

Parents drivers don't fasten them seat belts, don't use the children's holding devices and often roughly violate Traffic regulations in spite of the fact that in salon of the vehicle there are children.
As a measure for decrease in children's traumatism and death of minors the amendment to the legislation according to which children till 12 years can be transported only in the presence of the special children's holding device or other means allowing to fasten the child by means of seat belts is made to road accident in Kazakhstan.

Conclusions Situation with road traffic injuries of Kazakhstan citizen is alarming. It is necessary to increase road discipline of all participants of traffic - both drivers, and pedestrians.

\section{THE STRUCTURE AND REASONS OF ROAD ACCIDENTS IN KAZAKHSTAN}

'Leonid Karp, 'Mukhtar Abilmazhinov, ${ }^{2}$ Galina Jaxybekova. 'Astana Medical University; ${ }^{2}$ Research Institute of Traumatology and Orthopaedics

\subsection{6/injuryprev-2016-042156.513}

Background It is known that road traffic injuries (RTI) are the main problem in Public Health. Republic of Kazakhstan has the highest mortality rate from RTI in European region - 30.6 per 100000 population (world rate is 18.8).

Methods The analysis of the structure and reasons of RTI was carried out on the basis of official statistical data of 2014 .

Results According to data of a databank of the accounting of road accidents and persons, in them victims of all on the Republic 20.378 road accidents are registered. If to consider in a section of each area, the greatest number of road accidents continues to be made in the territory of Southern Kazakhstan. The most part of all road accidents resulted from accident of running-down pedestrians was $44.4 \%$. Further, because of collision of vehicles - $32.7 \%$ of road accidents, owing to capsizing $12.0 \%$, arrival on an obstacle $-5.0 \%$, accident of running-down cyclists $-1.8 \%$, arrival on the standing vehicles $-1.3 \%$. Noncompliance with Traffic regulations, namely excess of speed (26.4\%), transition by pedestrians of the carriageway in an unspecified place (10.4\%), departure on a strip of oncoming traffic (9.4\%), at journey of crosswalks $(8.7 \%)$, became the reasons of perfect road accidents. The greatest number of road accidents is made in settlements (48.7\%). Overwhelming majority (92.9\%) of road accident in Kazakhstan happened because of drivers while only $6.3 \%$ because of pedestrians and $0.8 \%$ because of cyclists. One of the reasons of growth of car accidents is that from 2007 to 2013 the quantity of units of motor transport in the country increased by 1.64 times.

Conclusions For improving the situation the electronic map of RTI is developed. Any citizen or road policeman could see the situation on RTI in all regions. This interactive system will help to prevent motor-vehicle accident traumatism and improve organisation of emergency medical aid to the victims.

\section{FACTORS INFLUENCING MOTORCYCLE ACCIDENTS IN NAY PYI TAW, MYANMAR}

${ }^{1}$ Aye Moe Moe Lwin, ${ }^{2}$ Yi Yi Win, ${ }^{2}$ Thinzar Aung, ${ }^{3}$ Thit Lwin. ${ }^{1}$ University of Public Health, Yangon, Myanmar; ${ }^{2}$ Department of Public Health, Nay Pyi Taw, Myanmar; ${ }^{3}$ University of Medicine 1, Yangon, Myanmar

\subsection{6/injuryprev-2016-042156.514}

Background Myanmar is one of the countries with high rates of road traffic accident morbidity and mortality in the world where injuries from motorcycle accidents contribute the highest incidence. 
Methods A hospital-based cross sectional descriptive study was conducted in Nay Pyi Taw with the aim of exploring the road user pattern, factors related to motorcycle accident and outcomes of accident among 171 motorcyclists, passengers and pedestrians admitted to two hospitals. Face to face interviews were conducted by using pre-tested questionnaire with motorcycle accident patients and their attendants.

Results Male, under 30 year age group, middle school level education and sale workers were most common victims. Motorcyclists were most at risk road users for accidents (57\%) and 40\% was due to fall or slipped motorcycles. Driving without licenses (31\%), drinking alcohol (19\%), high speeding (21\%) and overtracking (3.5\%), impaired visibility (9.4\%) and broken break or tires or engines $(4 \%)$ were associated with accidents. Forty eight percent of urban accident occurred on the straight roads where as $16 \%$ and $6 \%$ of rural accident occurred on rough and curved roads. Mortality rate was $9.9 \%$ whereas $4 \%$ was brought in dead cases. Nineteen percent treated as out-patients, 53\% as nonsevere in-patients and $18 \%$ was severe-in patients. Head injury and fracture in lower limbs were most common $36.3 \%$ and $30.4 \%$ respectively). Dead cases were due to head injury $(76.5 \%)$ and multiple injuries $(23.5 \%)$. Only $18 \%$ received first aids emergency treatment and $4.5 \%$ was sent to hospital with ambulance. Median risk cores of human factors, protective factors, vehicle factors and environmental factors were significantly higher on rural cases, pedestrian, severe in-patients and dead cases.

Conclusion Findings informed to responsible authorities for road traffic laws enforcement, intervention program development, emergency and medical services to reduce morbidity and mortality among road traffic injury patients.

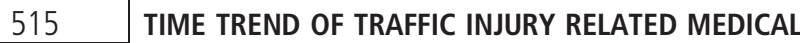 UTILISATION AND EXPENDITURES IN TAIWAN FROM $2003-2012$}

Ping-Ling Chen. Taipei Medical University, Taiwan

10.1136/injuryprev-2016-042156.515

Background Traffic injury is the leading external cause of unintentional injury in Taiwan. The aim of this study was to determine the utilisation of emergency-visit, hospitalisation, and medical expenditures by different type of vehicle crash.

Methods Claim data were collected from the Taiwan National Health Insurance Research Database for patients who were identified from the Taiwan National Traffic Accident Dataset from 2003 to 2012. Measurements included type of medical utilisation, medical expenditures, and type of vehicle crash. Frequency counts, percentages and 95\% confident interval were estimated for descriptive analyses. Mann-Kendall test was used to determine time trend of medical utilisation and medical expenditures by car types.

Results Over the period 2003 to 2012, the results of time trend test showed that the percentage of hospitalisation due to traffic injury had significantly decreased with years, however, the ERvisit utilisation increased from $27.4 \%$ in 2003 to $34.2 \%$ in 2012. In addition, both of the total medical expenditure of ER-visit and hospitalisation had significantly increased by years. In 2012, the total medical expenditure of ER-visit, hospitalisation was over 16.6 million US dollars and 47.4 million US dollars respectively. After stratification of car types, the ER-visit utilisation, total ER expenditure and total hospitalisation expenditure among twowheeler drivers remained significantly increased by years.
Although the ER-visit and medical utilisation among four-wheeler drivers was significantly decreased, the total medical expenditure of ER-visit among four-wheeler drivers had been significantly increased

Conclusions Effective traffic injury prevention programs are needed to develop for reducing the burden of public health and medical services.

\section{CHILDREN ARE WALKING! INNOVATIVE STUDY OF TRAVEL PATTERNS AND SAFETY}

${ }^{1}$ Sharon Levi, ${ }^{2}$ David Zaidel, ${ }^{3}$ Victoria Gitelman, ${ }^{4}$ Ido Prihed, ${ }^{1}$ Orly Silbinger. ${ }^{1}$ Beterem- Safe Kids Israel; ${ }^{2}$ Sight Ergonomics and Safety; ${ }^{3}$ Ran Naor Centrefor Road Safety Research, Technion; ${ }^{4}$ Prihed Geography and Survey Company

\subsection{6/injuryprev-2016-042156.516}

Background An increasing interest in the lifestyle and active mobility of children and continuing concern for their travel safety and secure environment requires detailed information about trip patterns and activities. There is little research on travel patterns of children, in particular during leisure hours. This study was designed to demonstrate child travel patterns and safety in Israel utilising advanced trip survey tools and methods.

Methods Phase 1 included a national self-report internet based travel survey as well as an innovative GPS based travel survey and follow up CAPI interview in Jerusalem with children age 612. Phase 2 included an in-depth study of pedestrian behaviour based on video analysis at major intersections and GPS based travel survey using cellular phones in three cities in central Israel. Results The findings indicate that walking is the most common mode of travel and children in Israel walk at a higher rate than their counterparts in other developed countries. The results include distances travelled, travel purposes and destinations, and differences among population groups. The study points to a number of risk-taking behaviours, including: dangerous walking while accompanied by an adult; vehicles not yielding to children at crosswalks; bicycling on roads and without helmets from a young age; and lack of safe pedestrian walkways.

Conclusions It is important to increase active mobility as part of a healthy lifestyle, however more efforts are needed to determine dangers to child pedestrians and promote safe walking. The study demonstrated feasibility of a GPS tracking method as well as the ability to obtain reliable activity and trip information from children as young as six years. The GIS spatial analysis provides an interesting and new perspective on child mobility and can influence both urban design and public health programming by identifying specific areas for behavioural and environmental treatment.

\section{THE CHALLENGES OF ENFORCING ROAD SAFETY POLICIES}

Gayle Di Pietro, Cristina Inclan, Cessie Petchi. Global Road Safety Partnership (GRSP)

\subsection{6/injuryprev-2016-042156.517}

Background Strong road safety policies that are strategically and effectively enforced optimise the safety of road users. In road safety, those responsible for enforcing the law are usually road police. In low and middle income countries, road police face many challenges as they are usually under-resourced and poorly trained to do the job of enforcement. 